\title{
Высокое ли экономическое неравенство в России? Вопросы измерения, показатели и их оценки ${ }^{1}$
}

\author{
А.А. САЛМИНА*
} *Алла Александровна Салмина - кандидат социологических наук, старший научный
сотрудник, Институт социального анализа и прогнозирования, Российская академия
народного хозяйства и государственной службы при Президенте РФ. Адрес: 119571,
Москва, просп. Вернадского, д. 82, стр. 1. E-mail: salmina-aа@ranepa.ru

Цитирование: Салмина А.А. (2021) Высокое ли экономическое неравенство в России? Вопросы измерения, показатели и их оценки // Мир России. Т. 30. № 3. С. 78-99. DOI: $10.17323 / 1811-038 X-2021-30-3-78-99$

Правильный выбор и корректная интерпретация методологии измерения неравенства важны для понимания особенностей и глубинь экономического неравенства в России. В данной статье рассмотрены оценки для России основных показателей неравенства, используемых в международных исследованиях. В первой части статьи представлены оценки неравенства в России по официальным статистическим данным Росстата и проанализированы альтернативные оченки по расчетам международньх организаций и отдельных групп ученых. Также исследуются показатели неравенства и ряд методологических аспектов измерения, которые необходимо учитывать при проведении расчетов. В рамках этого показано, как выгрранные показатели и используемые данные влияют на оценку неравенства. Дана оценка неравенства россиян по накопленному богатству $u$ описана специфика доходного неравенства российского населения, а именно наличие тяжельх хвостов распределений.

Во второй части статьи на данных ОЭСР проведено сравнение неравенства по доходам населения России и других стран по различным показателям. Согласно результатам, по большинству показателей Россия относится к группе стран с умеренно высоким неравенством по доходам (выше среднего уровня ОЭСР), а с учетом дооценки доходов самого богатого верхнего дециля на основе данных по богатству и налоговой статистике она становится одним из мировых лидеров по неравенству (как по оценкам Credit Suisse, так и Т. Пикетти).

1 Статья подготовлена в рамках выполнения научно-исследовательской работы государственного задания РАНХиГС. 
Автор приходит к выводу, что для получения объективной картины неравенства необходимо его оценивание одновременно по нескольким измерениям. Помимо стандартных показателей дифференцииции доходов (таких как коэффициент Дюнини и децильньй коэффициент), важно учитывать и ряд других показателей, которые отражают специфику распределения доходов в России, в частности, наличие тяжелого хвоста. Особый интерес представляют показатели, учитывающие особенности распределения доходов россиян в конияах распределений (коэффициент Пальма и др.) и чувствительные к изменению доходов среди бедных слоев населения (индекс Аткинсона, среднее логарифмическое отклонение).

Ключевые слова: неравенство, коэффициент Джини, доходы, богатство, налоги, Россия

\section{Проблема неравенства в России и в мире: недостаточное внимание к методологии оценки}

В последние годы неравенство было признано одной из главных мировых проблем, от решения которых зависит дальнейший экономический рост. Неравенство оказалось в центре внимания мировой интеллектуальной элиты [Vandenbroucke et al. 2015; Heckman 2011; Stowasser et al. 2011], политиков и широкой общественности. С начала 2000-х гг. Нобелевскими премиями были отмечены работы ряда экономистов, внесших значимый вклад в решение проблемы неравенства: Ангуса Дитона, Джозефа Стиглица, Ричарда Tалера [Deaton 2013; Stiglitz 2012; Thaler, Sunstein 2008]. Особую популярность проблема неравенства получила после публикации в 2014 г. работы французского экономиста Тома Пикетти «Капитал в XXI веке», в которой он заявил о дальнейшем неизбежном росте неравенства в условиях экономического спада и необходимости принятия срочных мер по перераспределению богатства для сохранения основ капитализма и демократии в мире [Piketty 2014]. Интерес к неравенству вырос и среди российских ученых [Рopova, Rudberg 2018; Капелюшников 2017; Капелюшников 2019; Овчарова и др. 2016; Малева, Авраамова 2014; Зубаревич 2013; Бурдяк 2015; Аганбегян 2017; Григорьев, Павлюшина 2018; Аникин, Тихонова 2016; Колмаков 2015; Лившии 2017; Любимов 2016; Джомо, Попов 2016; Шевяков, Кирута 2009].

В дискуссиях о необходимости сокращения уровня неравенства в России наименее изученная область - методология расчета его показателей. Чаще всего для измерения неравенства используется довольно ограниченный набор показателей, таких как коэффициент Джини, децильный коэффициент и др. При этом границы неравенства, которые считаются избыточными и требуют немедленного снижения, зачастую устанавливаются авторами произвольно и не всегда имеют за собой достаточную доказательную базу. В ряде случаев сокращение неравенства провозглашается самоцелью без анализа последствий для экономического развития, уровня бедности в стране и положения среднего класса. Такие выводы и призывы авторов представляются довольно опрометчивыми; на это указывают ведущие западные и российские ученые [Cochrane 2015; McCloskey 2014; Капелюшников 2017; Kaпелюшников 2019]. В таких условиях высок риск принятия политической элитой 
поспешных, необдуманных и радикальных мер, которые могут привести к негативным экономическим и социальным последствиям, поэтому методологии оценивания неравенства (как показателям, так и используемым данным) необходимо уделять повышенное внимание.

Наблюдение за отечественной полемикой о неравенстве в России как в среде ученых, так и в СМИ позволяет свидетельствовать об отсутствии единого понимания базовых понятий и показателей. Цель данной статьи - навести определенный порядок в этой сфере, показать различие оценок неравенства в России при использовании разных показателей неравенства, предложить их интерпретацию, сформулировать ряд положений, характеризующих ситуацию с неравенством в России, а также оценить особенности распределения доходов россиян по сравнению с населением других стран.

\section{Показатели неравенства. Что есть помимо Джини?}

Наиболее часто для измерения неравенства как в России, так и в международной практике используются коэффициент Джини, децильный коэффициент и показатели распределения доходов по процентным группам населения. Помимо них существует ряд других показателей, применение которых может быть полезным для оценки неравенства в России, среди которых коэффициент Пальма, индекс Аткинсона и др. Формулы для их расчета представлены в таблице 1. При отборе данных показателей мы учитывали их математические свойства, в частности их соответствие признакам «хороших» показателей неравенства ${ }^{2}$ (сюда не были включены наиболее простые показатели, такие как размах). Основой для отбора стал анализ опыта применения различных показателей неравенства в практике статистических служб отдельных стран и международных организаций.

Важным для нас было выделение тех показателей, которые учитывали бы специфику распределения доходов в России, в частности в его хвостах (в концах распределения - в левом и в правом) [Малева и др. 2020; Maleva et al. 2021]. Для этого, помимо стандартных показателей дифференциации доходов (таких как коэффициент Джини и децильный коэффициент), в таблицу 1 включены показатели, учитывающие особенности распределения доходов россиян в концах распределений, особенно среди бедных слоев населения (коэффициент Пальма), а также показатели концентрации доходов, чувствительные к изменению доходов среди бедных слоев населения (среднее логарифмическое отклонение, индекс Аткинсона).

\footnotetext{
2 В руководстве Всемирного банка (см. [Haughton, Khandker 2009, pp. 105-106]) по измерению бедности и неравенства на основании академических работ [Amiel, Cowell 1992] представлены критерии, которым должны соответствовать «хорошие» меры неравенства, а именно: 1) независимость от единиц измерения дохода (независимость от масштаба), 2) независимость от увеличения выборки путем ее повторения (например, если выборка населения страны репрезентативна, то рассчитанную по ней величину неравенства можно распространить на всю генеральную совокупность), 3) симметричность (если два человека в выборке «поменяются» своими доходами, то показатель неравенства не изменится), 4) чувствительность к перераспределению (принцип Пигу-Дальтона при перераспределении доходов от богатых к бедным показатель неравенства уменьшится), 5) статистическая тестируемость (возможность оценить доверительные интервалы и оценить статистическую значимость изменений с течением времени), 6) возможность разложимости/декомпозиции на составляющие неравенства.
} 


\section{Таблица 1. Показатели неравенства и их свойства}

\begin{tabular}{|c|c|c|}
\hline Показатель & Формула для расчета & Свойства \\
\hline Коэффициент Джини & $\begin{array}{l}\mathrm{G}=\frac{\sum_{i=1}^{n} \sum_{j=1}^{n}\left|y_{i}-y_{j}\right|}{2 n^{2} \bar{y}}, \\
\text { где } \bar{y}-\text { средний доход населения, } \\
\mathrm{y}_{\mathrm{i}}-\text { доход і-го индивида, } \\
\mathrm{y}_{\mathrm{j}}-\text { доход ј-го индивида, } \\
\mathrm{n}-\text { численность населения } \\
\mathrm{Gini}=1-\sum_{i=1}^{N}\left(x_{i}-x_{i-1}\right)\left(y_{i}+y_{i-1}\right) \mathrm{x}_{i} y_{i}\end{array}$ & $\begin{array}{l}\text { Более чувствителен } \\
\text { к неравенству } \\
\text { в средней части } \\
\text { распределения }\end{array}$ \\
\hline $\begin{array}{l}\text { Децильный коэффициент } \\
\text { дифференциации }\end{array}$ & $\begin{array}{l}K_{d}=\frac{d_{9}}{d_{1}}, \text { где } d_{9}-\text { минимальный доход } 10 \text {-го дециля, } \\
d_{1}-\text { максимальный доход 1-го дециля }\end{array}$ & $\begin{array}{l}\text { Сравнивает верхний } \\
\text { дециль с нижним }\end{array}$ \\
\hline $\begin{array}{l}\text { Децильный коэффициент } \\
\text { фондов }\end{array}$ & $\begin{array}{l}K_{\text {фондов }}=\frac{\bar{d}_{10}}{\bar{d}_{1}}, \text { где } \bar{d}_{10}-\text { средние доходы 10-го (самого верхнего) } \\
\text { дециля, } \bar{d}_{1}-\text { средние доходы 1-го (самого нижнего) дециля }\end{array}$ & $\begin{array}{l}\text { Сравнивает верхний } \\
\text { дециль с нижним }\end{array}$ \\
\hline $\begin{array}{l}\text { Квинтильный } \\
\text { коэффициент }\end{array}$ & $\begin{array}{l}K_{\text {quintile }}=\frac{\bar{q}_{5}}{\bar{q}_{1}}, \bar{q}_{1}-\text { средние доходы 1-го квинтиля, } \\
\bar{q}_{5}-\text { средние доходы 5-го квинтиля }\end{array}$ & $\begin{array}{l}\text { Сравнивает верхний } \\
\text { квинтиль с нижним }\end{array}$ \\
\hline Коэффициент Пальма & $\begin{array}{l}K_{\text {Palma }}=\frac{d_{10}}{d_{1}+d_{2}+d_{3}+d_{4}}, \text { где } d_{i}-\text { совокупные денежные доходы } \\
\text { і-го дециля }\end{array}$ & $\begin{array}{l}\text { Сравнивает доли } \\
\text { доходов верхнего } \\
\text { дециля и нижних } \\
40 \% \text { населения } \\
\end{array}$ \\
\hline $\begin{array}{l}\text { Среднее логарифмическое } \\
\text { отклонение }\end{array}$ & $\begin{array}{l}\quad G E(0)=M L D=\frac{1}{n} \sum_{i=1}^{n} \log \left(\frac{\bar{y}}{y_{i}}\right)=-\frac{1}{n} \sum_{i=1}^{n} \log \left(n s_{i}\right) \\
G E(0)=M L D=\frac{1}{N} \sum_{i=1}^{N} \ln \left(\frac{\bar{y}}{y_{i}}\right) \\
\text { где } \bar{y}-\text { средний доход населения, } \\
\begin{array}{l}\text { уі -доход і-го индивида, } \\
\mathrm{n}-\text { численность населения }\end{array}\end{array}$ & $\begin{array}{l}\text { Придает больший } \\
\text { вес неравенству } \\
\text { в нижней части } \\
\text { распределения }\end{array}$ \\
\hline Индекс Тейла & $\begin{array}{l}\qquad G E(1)=\text { THEIL }=\frac{1}{n} \sum_{i=1}^{n} \frac{y_{i}}{\bar{y}} \log \left(\frac{y_{i}}{\bar{y}}\right)=\sum_{i=1}^{n} s_{i} \log \left(n s_{i}\right) \\
\qquad G E(1)=T H E I L=\frac{1}{N} \sum_{i=1}^{N} \frac{y_{i}}{\bar{y}} \ln \left(\frac{y_{i}}{\bar{y}}\right) \\
\text { где } \bar{y}-\text { средний доход населения, } \\
\begin{array}{l}\mathrm{y}_{\mathrm{i}} \text {-доход і-го индивида, } \\
\mathrm{n}-\text { численность населения }\end{array}\end{array}$ & $\begin{array}{l}\text { Придает всем } \\
\text { частям } \\
\text { распределения } \\
\text { равные веса }\end{array}$ \\
\hline $\begin{array}{l}\text { Половина квадрата } \\
\text { коэффициента вариации }\end{array}$ & $\begin{array}{l}\qquad \begin{aligned} & G E(2)=\frac{1}{2 n \bar{y}^{2}} \sum_{i=1}^{n}\left(y_{i}-\bar{y}\right)^{2} \\
& G E(2)=C V^{2} / 2 \\
& \text { где } C V-\text { коэффициент вариации }\end{aligned}\end{array}$ & $\begin{array}{l}\text { Придает больший } \\
\text { вес неравенству } \\
\text { в верхней части } \\
\text { распределения }\end{array}$ \\
\hline Индекс Аткинсона & $\begin{array}{l}\qquad \mathrm{A}(\varepsilon)=1-\left[\frac{1}{n} \sum_{i=1}^{n}\left(\frac{y_{i}}{\bar{y}}\right)^{1-\varepsilon}\right]^{1 /(1-\varepsilon)} \\
\qquad A_{\varepsilon}=1-\left[\frac{1}{n} \sum_{i=1}^{n}\left[\frac{y_{i}}{\bar{y}}\right]^{1-\varepsilon}\right]^{\frac{1}{1-\varepsilon}} \\
\text { где n - численность населения, } \\
\mathrm{y}_{\text {i }} \text {-доход і-го индивида, } \\
\varepsilon \text { - параметр, который определяет, какая часть распределения } \\
\text { доходов более чувствительна к неравенству доходов. } \\
\text { Данный параметр задает исследователь }\end{array}$ & $\begin{array}{l}\text { Чем больше } \varepsilon, \text { тем } \\
\text { чувствительнее } \\
\text { к изменениям } \\
\text { в нижней части } \\
\text { распределения }\end{array}$ \\
\hline
\end{tabular}

Источник: составлено автором. 
Характеристиками концентрации неравенства являются коэффициент Джини, индекс Тейла и коэффициент Аткинсона, которые оценивают равномерность распределения неравенства среди всего населения страны. Они различаются степенью и характером зависимости от кривой распределения доходов. Коэффициент Джини присваивает разным частям распределения равные веса, в то же время, согласно некоторым исследованиям, он более чувствителен к изменениям в средней части распределения [Gastwirth 2017]. Индекс Тейла приписывает всем частям распределения равные веса. Среднее логарифмическое отклонение больше подходит для оценки неравенства в нижней части распределения, а половина квадрата коэффициента вариации в верхней части. Чувствительность к распределению доходов индекса Аткинсона различается в зависимости от включенного в формулу его расчета параметра неприятия неравенства $\varepsilon$, значение которого задается исследователем. Чем больше значения $\varepsilon$, тем индекс чувствительнее к изменениям доходов в нижней части распределения. В большинстве исследований применяются значения параметра $\varepsilon$, равные $0,5,1$ и 2 . Значение $\varepsilon$, равное нулю, означает, что индекс в равной мере чувствителен к изменениям доходов в любых частях распределения. В целом же чаще всего индекс Аткинсона (с параметрами $\varepsilon$, равными 1 и 2) используется для изучения неравенства в нижней части распределения.

Другие показатели в таблице 1 - коэффициенты дифференциации - сравнивают доли (или средние показатели) доходов отдельных квинтилей, процентилей населения. К ним относятся децильный коэффициент дифференциации, квинтильный коэффициент и коэффициент Пальма. Данные меры, в отличие от характеристик концентрации неравенства, не реагируют на изменения в средней части распределения. Коэффициент Пальма представляет собой соотношение между общими объемами денежных доходов $10 \%$ населения с самыми высокими доходами и $40 \%$ с самыми низкими доходами, что делает его подходящим для сравнения размера и динамики доходов между малообеспеченными слоями и самым богатым верхним децилем.

Помимо показателей, представленных в таблице 1, существует и ряд других, используемых в академических исследованиях, но редко применяемых для межстрановых сравнений. Мерой оценки неравенства в верхних хвостах распределений является хвостовой индекс. Существуют различные способы его оценки - ядерные оценки, оценка Хилла [Hill 1975] и др. Наиболее популярной их них стала оценка Хилла (1975), которая вычисляется по формуле: $\widehat{\zeta}_{\text {Hill }}=\mathrm{n} / \sum_{\mathrm{t}=1}^{\mathrm{n}}\left[\log \left(\mathrm{X}_{\mathrm{t}}\right)-\log \left(\mathrm{X}_{(\mathrm{n}+1)}\right)\right]$ [Ibragimov M., Ibragimov R. 2018, p. 829], где $\mathrm{n}$ - количество статистик высшего порядка, используемых в оценке. Хвостовой индекс может быть использован для определения тяжести хвостов распределения и количества конечных моментов. Меньшие значения хвостового индекса $\bar{\zeta}$ соответствуют большей тяжести хвостов и более высокой вероятности наличия выбросов и экстремальных значений.

Если говорить в терминах теории вероятностей, хвост распределения является тяжелым, когда он экспоненциально не ограничен, т. е. у него более тяжелый хвост, чем у экспоненциального распределения. Согласно определению, распределение функции $\mathrm{f}$ имеет тяжелый хвост, если и только если: 
$\lim _{x \rightarrow \infty} \sup f(x) e^{\lambda x}=\infty$ для всех $\lambda>0$ [Foss et al. 2013, р. 8], т. е. хвост тяжелее тогда, когда быстрее уменьшается вероятность при удалении от центра распределения ${ }^{3}$.

\section{Оценки неравенства в России по методике Росстата}

Показатели неравенства Росстата рассчитаются на данных выборочного «Обследования бюджетов домашних хозяйств» (ОБДХ). В качестве источника оценок среднедушевых доходов населения используются данные Баланса денежных доходов и расходов населения (БДДР). Для всех обследований домашних хозяйств Росстат (с 1997 г.) проводит процедуру согласования с данными БДДР, исходя из гипотезы о равенстве мод [Методологические положения 2015, с. 19]. Оценки неравенства Росстат рассчитывает не только по доходам, но и по потреблению, которое также измеряется на данных ОБДХ.

Отдельное направление составляют альтернативные официальным данным Росстата оценки неравенства в России [Кислищына 2003; Шевяков, Кирута 2002; Шевяков, Кирута 2009; Бутаева 2017; Малева и др. 2021]. Чаще всего в таких исследованиях для расчетов используются данные Лонгитюдного обследования домохозяйств РМЭЗ НИУ ВШЭ (далее - РМЭЗ) [Commander et al. 1999; Yemtsov 2008]. Также с недавнего времени стали доступны данные выборочного наблюдения доходов населения и участия в социальных программах Росстата $(\mathrm{BHДН),} \mathrm{репрезентативного} \mathrm{по} \mathrm{регионам} \mathrm{России.} \mathrm{В} \mathrm{нашей} \mathrm{работе} \mathrm{мы} \mathrm{ограничимся}$ лишь кратким описанием дискуссии о надежности оценок Росстата и используемых методах оценки распределения доходов. Предметом данного исследования является сравнение оценок неравенства в зависимости от используемых источников данных и различных показателей неравенства; данному аспекту уделяется существенно меньше внимания как в российской, так и зарубежной литературе.

Росстат рассчитывает следующие показатели дифференциации доходов:

• коэффициент Джини («индекс концентрации доходов»),

- кривую Лоренца,

- децильный коэффициент дифференциации,

- коэффициент фондов («коэффициент дифференциации доходов»).

В таблице 2 представлены официальные оценки Росстата некоторых показателей неравенства по доходам и по заработной плате за 2017 г. Показано, что децильный коэффициент фондов по доходам $(15,3)$ немного выше, чем по заработной плате $(14,1)$. В целом же показатели неравенства по доходам и заработной плате почти не отличаются; размер медианных значений заработной платы и дохода меньше средних значений, т. е. большинство россиян имеют доходы и заработок ниже средних по стране.

\footnotetext{
3 Оценки хвостового индекса по формуле Хилла на данных распределения доходов россиян приведены в статье «Робастный анализ динамики неравенства доходов в России: подходы, основанные на t-статистике» [Ibragimov et al. 2012], в которой показаны тяжеловесность хвостов распределения доходов российских домохозяйств и сходство в этом с экономически развитыми странами мира.
} 
Таблица 2. Показатели дифференциации денежных доходов и заработной платы россиян по официальным оценкам Росстата, 2017 г.

\begin{tabular}{|l|c|c|}
\hline Показатели & Доходы & Заработная плата \\
\hline Среднедушевой доход / заработная плата всего населения, руб. в месяц & 31421,6 & 38900 \\
\hline Медианный среднедушевой доход / заработная плата всего, руб. в месяц & 23561,3 & 28345 \\
\hline Модальный среднедушевой доход / заработная плата всего, руб. в месяц & 13247,8 & 17630 \\
\hline Соотношение медианы со среднедушевым показателем всего, \% & 75 & 73 \\
\hline $\begin{array}{l}\text { Соотношение моды со среднедушевым денежным доходом/ заработной } \\
\text { платой, \% }\end{array}$ & 42,2 & 45 \\
\hline $\begin{array}{l}\text { Доля доходов / заработной платы 1-го квинтиля (нижней 20-процентной } \\
\text { группы населения) }\end{array}$ & 5,4 & 5,8 \\
\hline Доля 2-го квинтиля & 10,1 & 10,2 \\
\hline Доля 3-го квинтиля & 15,1 & 14,7 \\
\hline Доля 4-го квинтиля & 22,6 & 21,3 \\
\hline Доля 5-го квинтиля (нижней 20-процентной группы населения) & 46,8 & 48 \\
\hline Децильный коэффициент фондов, раз & 15,3 & 14,1 \\
\hline Коэффициент Джини & 0,41 & 0,415 \\
\hline
\end{tabular}

Примечание: в таблице 2 также представлены меры центральной тенденции - мода и медиана. В соответствии с методологией Росстата денежные доходы населения включают оплату труда наемных работников, доходы от предпринимательской и иной производственной деятельности, социальные выплаты (пенсии, пособия, стипендии и др.); доходы от собственности и прочие денежные поступления.

Источник: Росстат // https://rosstat.gov.ru/free_doc/new_site/population/bednost/tabl/tab-bed1-2-4.htm

При выборе показателей измерения неравенства необходимо учитывать особенности структуры доходов. Распределение доходов в России по квинтилям позволяет говорить о том, что полезным может быть использование данных, которые учитывают «однородность» (низкую дифференциацию) по доходам нижних слоев населения: в частности, таким показателем является коэффициент Пальма, который представляет собой соотношение между общими объемами денежных доходов $10 \%$ населения с самыми высокими доходами и $40 \%$ с самыми низкими доходами.

\section{Сравнение оценок коэффициента Джини по данным Росстата и международных организаций}

Помимо данных официальной российской статистики по неравенству, существуют также альтернативные оценки как международных статистических служб, так и отдельных групп ученых. Рассмотрим различия оценок неравенства в зависимости от используемых данных и способов построения распределения доходов 
на примере коэффициента Джини. На рисунке 1 представлено сравнение оценок коэффициента Джини по данным Росстата, Всемирного банка (база микроданных PovcalNet) и других международных организаций. На протяжении практически всего временного отрезка, отображенного на рисунке 1 , неравенство по оценкам Всемирного банка ниже, чем по официальным данным Росстата. Обращает на себя внимание тот факт, что наибольшие расхождения оценок наблюдались в периоды экономических кризисов. Различия оценок связаны, во-первых, с методологией дооценки доходов, которую использует Росстат, во-вторых, с различными источниками данных. Если Росстат рассчитывает коэффициент Джини на данных денежных доходов населения, то в базе микроданных PovcalNet Bсемирного банка оценки приведены по потреблению. Помимо этого, в некоторой мере различается и методология расчета. Всемирный банк для построения показателей неравенства использует официальные статистические наблюдения и опросы домохозяйств, публикуемые национальными статистическими службами стран. В то же время в связи с недоступностью оперативных данных опросов домохозяйств при построении показателей бедности и неравенства Всемирный банк применяет методы интерполяции и экстраполяции на данных за предыдущие годы.

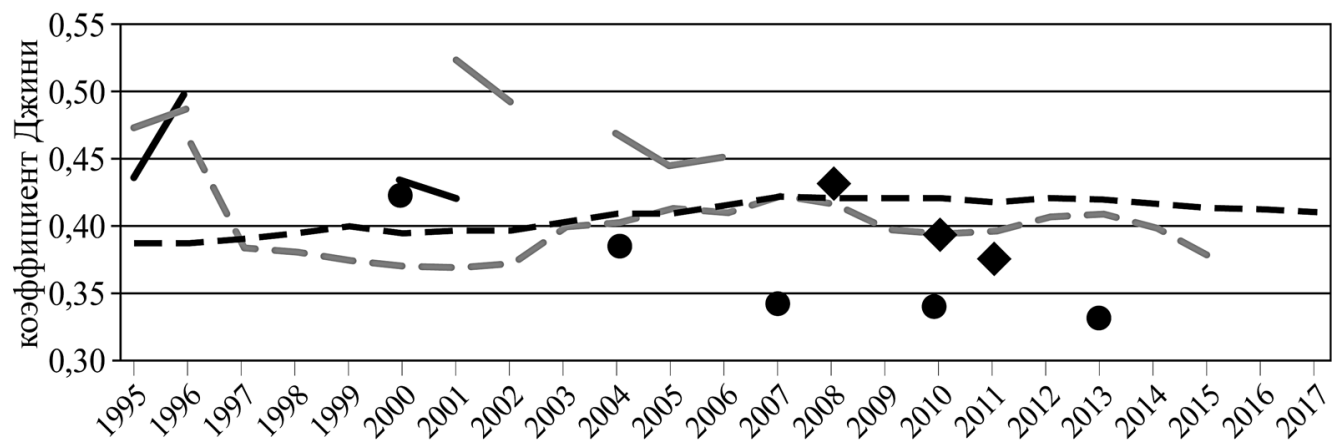

- - Росстат - располагаемый доход на душу Bсемирный банк (PovcalNet) - потребление на душу (шкала эквивалентности - размер домохозяйства)

- LIS - располагаемый доход на душу (шкала эквивалентности - размер домохозяйства) $\mathrm{OOH}$ - располагаемый доход на душу (шкала эквивалентности - размер домохозяйства) $\mathrm{OOH}$ - заработная плата доо вычета налогов и социальных отчислений, индивиды

ОЭСР - денежные доходы располагаемые, домохозяйства (шкала эквивалентности)

Рисунок 1. Коэффициент Джини в России по оценкам различных статистических организаций

Источник: Росстат; базы данных PovcalNet Всемирного банка;

всемирная база данных о неравенстве доходов (англ. - World Income Inequality Database, сокращенно - WIID); Фонд ООН помощи детям (Transformative Monitoring for Enhanced Equity);

Люксембургское исследование доходов

(англ. - Luxembourg Income Study, на рисунке - LIS). 
Различается и динамика коэффициента Джини по оценкам Росстата и других организаций. Официальные оценки Росстата были относительно стабильны на уровне 0,39-0,41 с 1995 по 2017 г., в то время как оценки Всемирного банка и Люксембургского исследования доходов испытывали заметные колебания и показывали разнонаправленную динамику. По данным Всемирного банка, коэффициент Джини увеличился с 0,37 в 1999 г. до 0,41 в 2013 г., правда, за два последующих года уменьшился до 0,38. Наибольшее снижение коэффициента Джини за период с 2000 по 2013 г. показали данные Люксембургского исследования доходов - он упал с 0,42 до 0,33 . Отметим, что оценки неравенства по России Люксембургского исследования доходов за 2000-2010 гг. основаны на данных РМЭЗ НИУ ВШЭ, с 2011 г. - на данных ВНДН Росстата. В связи с этим небольшое снижение значения показателей в период с 2010 по 2013 г. может быть связано с различием используемых данных.

В целом оценки Джини по расчетам Всемирного банка, как правило, ниже, чем у Росстата. В то же время на протяжении всего периода с 2003 по 2014 г,, за исключением 2009-2011 гг, они были очень похожи. Следует уточнить, что оценки Росстата построены на данных о доходах, в то время как оценки Всемирного банка, представленные на рисунке $1,-$ на данных по потреблению (расходам). Поэтому мы предполагаем, что эти различия связаны с разным потребительским поведением населения в периоды кризисов.

Рисунок 1 наилучшим образом демонстрирует важность использования одинакового источника данных по неравенству как для анализа динамики, так и для межстрановых сопоставлений. В силу специфики дооценки официальных показателей неравенства Росстатом, их прямое сопоставление с оценками статистических служб других стран представляется некорректным, и для сравнения необходимо оперировать оценками, полученными с использованием единых способов расчета и на одинаковом типе данных (потребления или доходов).

\section{Оценки неравенства в России по рыночному и располагаемому доходам}

Согласно принятой в странах ОЭСР методологии, показатели неравенства, в частности коэффициент Джини, для рыночных и располагаемых доходов населения рассчитываются на регулярной основе. Располагаемый доход получается после вычета из рыночного дохода налогов и социальных взносов домохозяйств в системы социального обеспечения, что позволяет оценивать вклад в снижение неравенства перераспределения доходов через бюджетные трансферты и налоговую политику. В России такие оценки еще не вошли в регулярную практику, хотя в последние годы были предприняты попытки получить экспериментальные оценки как Росстатом, так и отдельными группами ученых.

Значения коэффициента Джини по оценкам ОЭСР для России представлены на рисунке 2. Если за период с 2008 по 2011 г. коэффициент Джини в России по рыночному доходу почти не изменился (2008 г. - 0,486, 2011 г. - 0,485), то по располагаемому снизился на 12\% (2008 г. - 0,428, 2011 г. - 0,376). Можно предполагать, что данное снижение коэффициента Джини произошло за счет роста социальных трансфертов. 


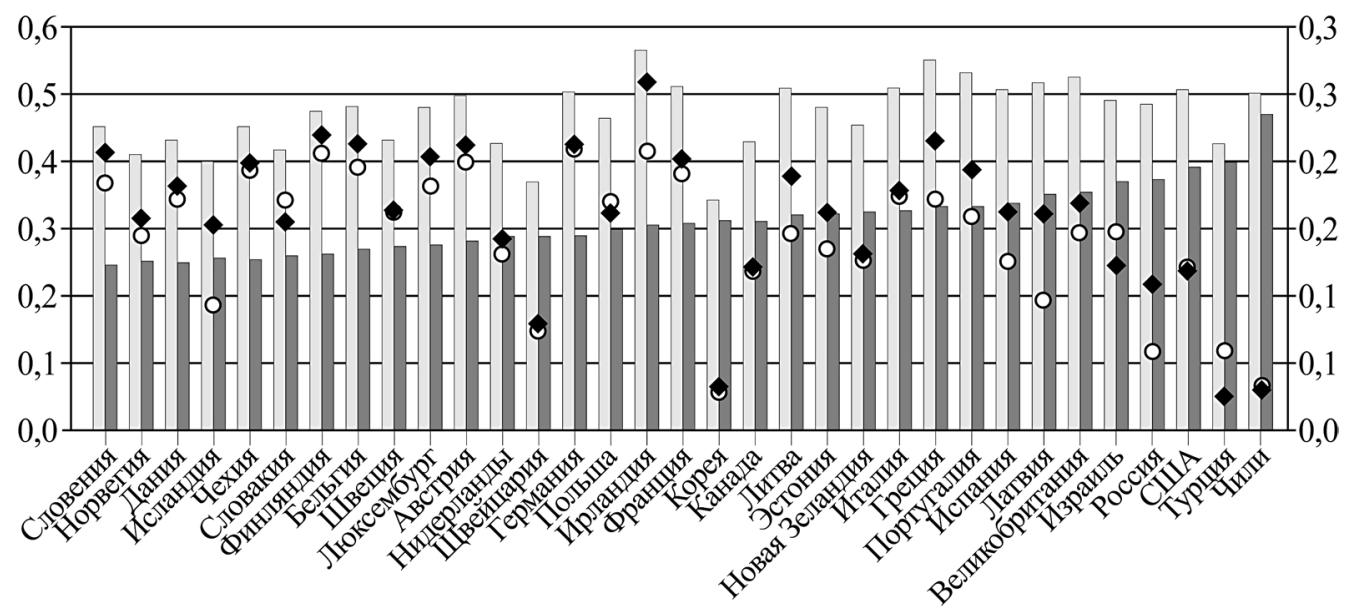

$\square$ коэффициент Джини по рыночному доходу, 2011 г.

коэффициент Джини по располагаемому доходу, 2011 г.

О разница коэффициентов Джини по рыночному и располагаемому доходу, 2008 г.

๑ разница коэффициентов Джини по рыночному и располагаемому доходу, 2011 г.

Рисунок 2. Коэффициент Джини по рыночному и по располагаемому доходам, 2011 г. Источник: база данных распределения доходов ОЭСР ${ }^{4}$.

Рисунок 2 наглядно демонстрирует влияние перераспределительной политики стран на неравенство, которое в России по рыночному доходу несущественно отличается от большинства европейских стран. Так, значение коэффициента Джини по рыночному доходу в России $(0,48)$ не выше, чем в США $(0,51)$, Германии $(0,51)$ и Франции $(0,52)$. Заметные различия в неравенстве между странами появляются после перерасчета коэффициента Джини по располагаемому доходу: в Великобритании, стране с неолиберальной социальной политикой, после переоценки по располагаемому доходу коэффициент Джини уменьшается с 0,52 до 0,35, в США - с 0,51 до 0,39, в Германии - с 0,51 до 0,29, во Франции - с 0,52 до 0,31.

\section{Как меняется уровень неравенства при оценке по богатству и с учетом налоговых данных}

На сегодняшний день основным источником внутристрановых данных по доходам и потреблению являются выборочные опросы домохозяйств, но при этом во всех странах опросы имеют главный недостаток - неудовлетворительную представленность обеспеченных слоев населения; способы дооценки доходов на основании макропоказателей также не гарантируют достоверность полученных данных. Для решения этого вопроса исследователи ищут другие способы учета доходов

4 OECD Income Distribution Database // http://oe.cd/idd 
наиболее состоятельных слоев, например, используются данные о налоговых отчислениях граждан. И несмотря на существование эмпирических доказательств того, что самые богатые граждане часто уклоняются от уплаты налогов [Zucman 2015], все-таки принято считать, что использование этих данных позволяет получить более объективные оценки ${ }^{5}$.

Альтернативой денежного дохода для оценок неравенства является использование данных о накопленном богатстве, и в последние годы измерению неравенства по богатству уделяется все большее внимание как со стороны международных исследовательских организаций, так и отдельных групп ученых. В известной статье С. Гуриева и А. Рачинского представлены результаты расчетов коэффициента Джини для России с учетом доходов самых богатых жителей г. Москвы. Для этой цели авторы использовали набор данных о доходах московских налогоплательщиков за 2004 г. Согласно их расчетам, коэффициент Джини в России в 2004 г. составил около 0,65, что существенно выше официальных оценок Росстата (0,41 в 2004 г.), при этом верхним 10\% россиян принадлежало около 50\% совокупных доходов [Guriev, Rachinsky 2009].

Похожие оценки на более поздних данных представлены в получившей большую известность статье Т. Пикетти, Ф. Новокмета и Г. Цукмана «От Советов до олигархов: неравенство и собственность в России в 1905-2016 гг.». По их расчетам, доля богатства верхнего дециля в 2016 г. составляла 45,5\%, а самому верхнему 1\% принадлежало 20,2\% совокупного богатства [Novokmet, Piketty, Zucman 2018]. В качестве источника данных о доходах домашних хозяйств авторы использовали РМЭЗ за период 1994-2015 гг., ОБДХ Росстата за 1989-2015 гг., а также сопоставимые советские обследования за 1980, 1985 и 1988 гг. Оба обследования, по мнению Т. Пикетти, Ф. Новокмета и Г. Цукмана, обеспечивают приемлемое описание распределения доходов россиян ниже 90-го процентиля. Для расчета доходов десятого дециля были использованы таблицы со статистикой подоходного налога, доступные за период с 2008 по 2015 г. Чтобы на их основе достроить данные о доходах россиян, были применены обобщенные методы интерполяции Парето и кусочно-линейные поправочные коэффициенты. В своей статье Т. Пикетти, Ф. Новокмет и Г. Цукман утверждают, что официальные оценки Росстата, основанные на выборочных опросах, существенно занижают рост неравенства в России с 1990 г. кам, неравенство за этот период в России выросло значительно больше, чем в других постсоциалистических странах Восточной Европы и в Китае [Novokmet, Piketty, Zucman 2018].

Самым обширным источником информации о глобальном благосостоянии домохозяйств является доклад о глобальном богатстве (Global Wealth Report) банка Credit Suisse, публикуемый ежегодно с 2010 г. Согласно последнему выпуску доклада, Россия имеет наибольшее в мире неравенство по доле богатства, принадлежащему самому состоятельному 1\% населения (рисунок 3). Самые богатые $1 \%$ россиян владеют 57,1\% активов страны (верхние 5\% - 73,7\% активов, верхние $10 \%-81,8 \%$ ). На втором и третьем месте после России находится Индия и Бразилия, в которых самому богатому 1\% принадлежат 52\% и 43\% активов соответственно [Credit Suisse Global Wealth Report 2018, p. 9]. Согласно

\footnotetext{
5 Данные о налоговых отчислениях граждан использованы для измерения неравенства в исследованиях [Atkinson et al. 2011; Lakner, Milanovic 2013].
} 
коэффициенту Джини, рассчитанному по богатству, Россия занимает второе место в мире (значение коэффициента - 0,875) после Тайланда $(0,902)$; США на пятом месте $(0,852)$.

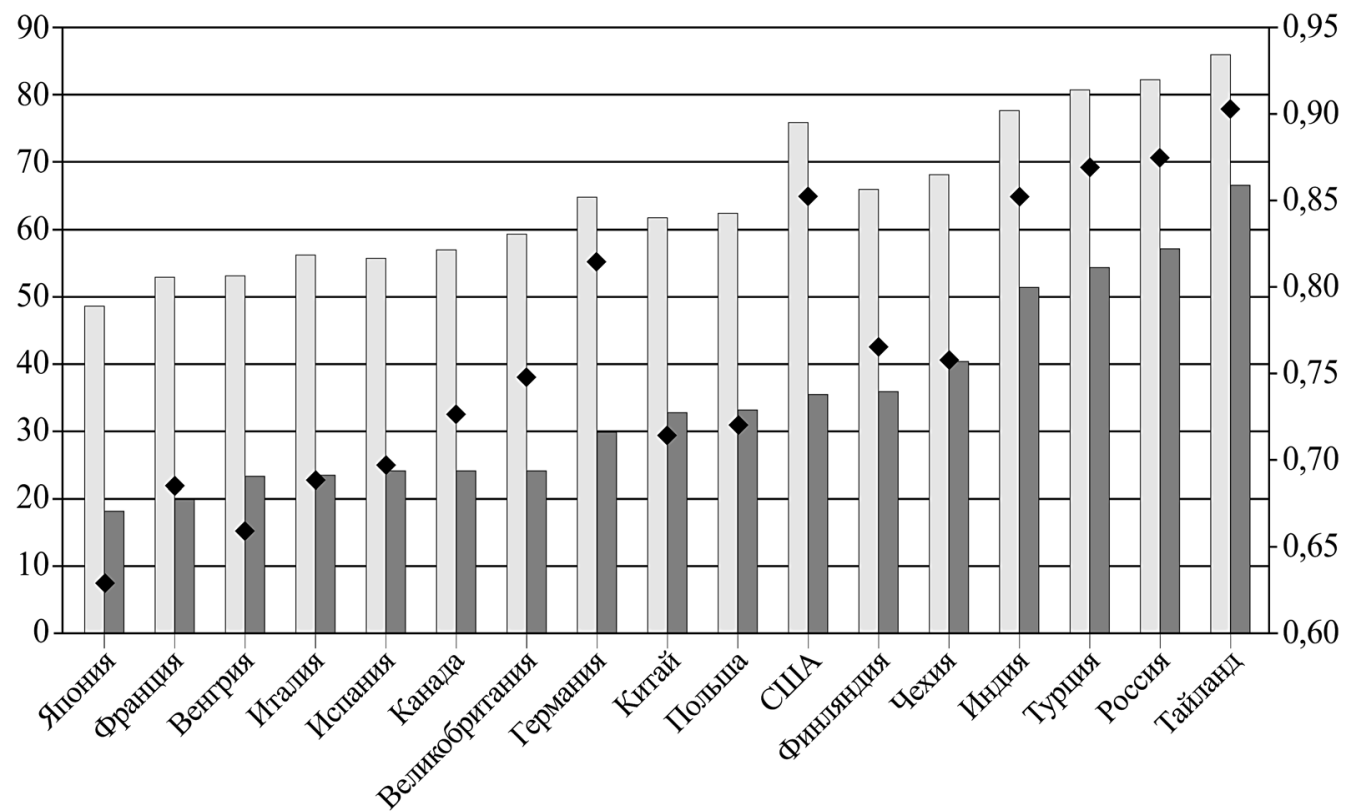

$\square$ доля богатства верхних 10 процентов, \% (левая шкала)

$\square$ доля богатства верхнего 1 процента, \% (левая шкала)

- коэффициент Джини по богатству (правая шкала)

Рисунок 3. Индекс Джини по богатству и доля богатства, принадлежащая верхнему 1\% населения, 2018 г.

Источник: [Credit Suisse Global Wealth Report 2018].

С высокой концентрацией российских доходов и богатств в верхних слоях населения связана и особенность распределения - наличие так называемого правого тяжелого хвоста. Оценки, подтверждающие это, получены в статьях упомянутых ранее авторов [Ibragimov et al. 2012; Ibragimov M., Ibragimov R. 2018]. Наличие тяжелого правого хвоста распределения является особенностью распределения доходов населения многих стран с высокими показателями неравенства и малочисленным средним классом. По оценкам Марата Ибрагимова и Рустама Ибрагимова, оценки хвостового индекса для распределения российских доходов находятся в том же диапазоне, что и для стран с развитыми экономиками (от 1,5 до 3) [Ibragimov M., Ibragimov R. 2018]. Это свидетельствует о том, что неравенство в правом хвосте распределения доходов (среди богатых), измеряемое хвостовыми индексами, в России и в экономически развитых странах схоже. На основе описанных выше оценок неравенства по богатству можно предполагать, что по богатству выраженность тяжелого правого хвоста распределения в России становится еще более очевидной. 
Специфика распределения доходов россиян, а именно наличие тяжелого хвоста, требует включения в анализ показателей, измеряющих неравенство в концах распределения, в т. ч. среди бедных слоев. При расчете коэффициента Джини разные части распределения учитываются с равными весами, что, говоря простым языком, указывает на «среднюю температуру по больнице». В связи с этим для оценки неравенства в России мы предлагаем использовать более широкий круг показателей, учитывающих и наличие тяжелых хвостов.

\section{Неравенство в России по доходам - умеренно высокое}

В этом разделе описывается неравенство в российских домохозяйствах в терминах различных показателей неравенства и сравнивается с оценками других европейских стран. Как уже отмечалось выше, мы можем сопоставлять только те показатели, которые имеют одинаковый источник данных и рассчитаны за один период времени. В этом разделе для сравнения показателей неравенства в России и других странах мы будем использовать данные ОЭСР и Люксембургского исследования доходов, что позволит получить общую картину неравенства в России.

Для сопоставления России с другими странами были использованы данные за 2011 г., т. к. у ОЭСР более поздние оценки по РФ отсутствуют. Как видно из крайней правой колонки таблицы 3, за период с 2008 по 2011 г. немного снизились почти все показатели неравенства. И вполне объяснимо, что степень изменения показателей немного различается, т. к. доходы разных децилей росли в различной степени, и больше всего (в 0,7 раз) уменьшился коэффициент Пальма (определение данного и других показателей неравенства - см. в таблице 1): в 2011 г. индекс Пальма в России составил 1,59 (для сравнения: в 2008 г. - 2,15, в 2010 г. - 1,83). Более устойчивым к изменениям оказался коэффициент дифференциации P50/P10 (отношение медианы к самому высокому доходу самого бедного первого дециля) и коэффициент Джини, рассчитанный по рыночному доходу (до вычета налогов и платежей).

В таблице 4 (см. стр. 92) представлено распределение стран ОЭСР и ряда других, включая Россию 6 , по разным показателям неравенства, поскольку учет широкого круга данных может демонстрировать более полную картину неравенства (с учетом разных его аспектов). Помимо этого, ранжирование стран дает оценку того, насколько значения показателей в РФ являются высокими в сравнительной перспективе. Место России в рейтинге стран (всего 41 страна) совпадает по коэффициенту Джини по располагаемому доходу, коэффициенту Пальма и децильному коэффициенту дифференциации доходов Р90/Р10; по этим показателям Россия находится на 33-м месте. Сильнее всего снижает место России в рейтинге стран ОЭСР коэффициент дифференциации Р90/Р50, представляющий собой отношение минимального размера доходов $10 \%$ наиболее богатых жителей к медианному доходу.

По сравнению с другими странами наиболее низкий уровень неравенства из всех рассмотренных показателей показывает коэффициент Джини по рыночному доходу, построенный на данных дохода до выплаты налогов и социальных транс-

6 Помимо стран ОЭСР, она включает также оценки для Бразилии, Китая, Коста-Рики, Индии и России. 
фертов, и коэффициент Джини по рыночному доходу и коэффициент Аткинсона с параметром эпсилон, равным единице, придающий больший вес различию доходов в нижнем конце распределения. Можно предполагать, что в России неравенство среди бедных слоев населения менее выражено по сравнению с остальной частью распределения доходов. Если по коэффициенту Джини по рыночному доходу Россия находится на 21-м месте из 41 страны, то по располагаемому доходу на 33-м. Если посмотреть на разницу численных значений данных двух показателей, то во всех странах, включая Россию, уровень неравенства после вычета налогов и учета социальных трансфертов снижается, хотя и в разной степени. В России коэффициент Джини по рыночному доходу после пересчета по располагаемому доходу уменьшается на 0,11 (с 0,485 до 0,376$)$, в то время как в среднем в странах ОЭСР - на 0,16 . Это отражает больший вклад фискальной политики в снижение неравенства стран ОЭСР по сравнению с Россией; сильнее всего снижение отмечается в Ирландии $(-0,26)$, меньше всего - в Индии $(-0,01)$.

\section{Таблица 3. Показатели неравенства в России}

\begin{tabular}{|c|c|c|c|c|}
\hline Показатели неравенства & 2008 г. & 2010 г. & 2011 г. & $\begin{array}{c}\text { Изменение } \\
\text { в 2008-2011 гг., раз }\end{array}$ \\
\hline Коэффициент Джини (располагаемый доход) & 0,428 & 0,396 & 0,376 & 0,9 \\
\hline $\begin{array}{l}\text { Стандартная ошибка коэффициента Джини } \\
\text { (для располагаемого дохода) }\end{array}$ & 0 & 0 & 0,009 & - \\
\hline Коэффициент Джини (рыночный доход) & 0,486 & 0,481 & 0,485 & 1,0 \\
\hline Коэффициент Пальма (располагаемый доход) & 2,15 & 1,83 & 1,59 & 0,7 \\
\hline $\begin{array}{l}\text { Децильный коэффициент дифференциации - } \\
\text { P90/Р10 (располагаемый доход) }\end{array}$ & 6,9 & 6 & 5,9 & 0,9 \\
\hline $\begin{array}{l}\text { Децильный коэффициент дифференциации - } \\
\text { Р90/Р50 (располагаемый доход) }\end{array}$ & 2,8 & 2,6 & 2,5 & 0,9 \\
\hline $\begin{array}{l}\text { Децильный коэффициент дифференциации - } \\
\text { P50/P10 (располагаемый доход) }\end{array}$ & 2,5 & 2,3 & 2,4 & 1,0 \\
\hline $\begin{array}{l}\text { Квинтильный коэффициент дифференциации - } \\
\text { S80/S20 (располагаемый доход) }\end{array}$ & 9 & 7,6 & 7,1 & 0,8 \\
\hline Индекс Аткинсона $(\varepsilon=0,5)$ & 0,10 & 0,09 & 0,11 & 1,1 \\
\hline Индекс Аткинсона $(\varepsilon=1,0)$ & 0,20 & 0,19 & 0,20 & 1,0 \\
\hline
\end{tabular}

Примечание: коэффициент Джини по рыночному доходу построен на данных дохода до выплаты налогов и социальных трансфертов.

Источник: Оценки индекса Аткинсона приведены по данным Люксембургского исследования доходов; другие показатели - база данных распределения доходов ОЭСР.

Неравенство по коэффициенту Джини по располагаемому доходу выше российского уровня $(0,37)$ в США $(0,39)$, Турции $(0,40)$, Мексике $(0,46)$, Чили $(0,47)$, Коста-Рике $(0,48)$, Бразилии $(0,48)$, Индии $(0,50)$ и Китае $(0,51)$. Наиболее сильные отличия России от средних показателей стран ОЭСР наблюдаются по децильному коэффициенту дифференциации Р90/Р10 (в России выше в 1,38 раз), квинтильному 
коэффициенту S80/S20 (в 1,31 раза), по коэффициенту Пальме (в 1,29 раза) и по коэффициенту дифференциации Р90/P50 (в 1,26 раз); наименее сильные отличия - по коэффициенту Джини по рыночному доходу (в 1,03 раза).

\section{Таблица 4. Сравнение различных показателей неравенства по доходам населения Рос- сии и других европейских стран, 2011 г.}

\begin{tabular}{|c|c|c|c|c|c|c|c|c|c|}
\hline \multirow{2}{*}{ Показатели } & \multicolumn{3}{|c|}{ Рейтинг } & \multicolumn{4}{|c|}{ Значения показателей } & \multicolumn{2}{|c|}{ Соседи России в рейтинге } \\
\hline & $\begin{array}{l}\text { Poc- } \\
\text { сия }\end{array}$ & США & \begin{tabular}{|c|} 
Гер- \\
мания
\end{tabular} & $\begin{array}{l}\text { Рос- } \\
\text { сия }\end{array}$ & США & $\begin{array}{c}\text { Гер- } \\
\text { мания }\end{array}$ & ОЭСР & Ниже & Выше \\
\hline $\begin{array}{l}\text { Уровень бедности } \\
\text { после вычета налогов } \\
\text { и трансфертов (черта } \\
\text { бедности - } 60 \% \text { ) }\end{array}$ & 31 & 33 & 9 & 0,219 & 0,242 & 0,148 & 0,18 & $\begin{array}{c}\text { Корея }(0,209), \\
\text { Испания }(0,214), \\
\text { Япония }(0,219)\end{array}$ & $\begin{array}{c}\text { Греция }(0,221), \\
\text { США }(0,242), \\
\text { Чили }(0,252)\end{array}$ \\
\hline $\begin{array}{l}\text { Коэффициент Джини } \\
\text { (располагаемый } \\
\text { доход) }\end{array}$ & 33 & 34 & 15 & 0,376 & 0,389 & 0,291 & 0,31 & $\begin{array}{c}\text { Латвия }(0,352), \\
\text { Великобри- } \\
\text { тания }(0,354), \\
\text { Израиль }(0,371)\end{array}$ & $\begin{array}{l}\text { США }(0,389) \text {, } \\
\text { Турция }(0,403) \text {, } \\
\text { Мексика }(0,457)\end{array}$ \\
\hline $\begin{array}{l}\text { Коэффициент Джини } \\
\text { (рыночный доход) }\end{array}$ & 21 & 30 & 27 & 0,485 & 0,508 & 0,505 & 0,47 & $\begin{array}{c}\text { Эстония }(0,484), \\
\text { Финлян- } \\
\text { дия }(0,485), \\
\text { Венгрия }(0,485)\end{array}$ & $\begin{array}{l}\text { Бельгия }(0,486), \\
\text { Япония }(0,488), \\
\text { Израиль }(0,494)\end{array}$ \\
\hline $\begin{array}{l}\text { Коэффициент } \\
\text { Пальма (располагае- } \\
\text { мый доход) }\end{array}$ & 33 & 34 & 14 & 1,59 & 1,74 & 1,06 & 1,24 & $\begin{array}{c}\text { Латвия }(1,42), \\
\text { Великобри- } \\
\text { тания }(1,47), \\
\text { Израиль }(1,54)\end{array}$ & $\begin{array}{l}\text { США }(1,74) \text {, } \\
\text { Турция }(1,89), \\
\text { Мексика }(2,54)\end{array}$ \\
\hline $\begin{array}{l}\text { Децильный } \\
\text { коэффициент } \\
\text { дифференциации } \\
\text { P90/P10 }\end{array}$ & 33 & 35 & 13 & 5,9 & 6,1 & 3,5 & 4,28 & $\begin{array}{c}\text { Япония }(5,1), \\
\text { Испания }(5,1), \\
\text { Израиль }(5,9)\end{array}$ & $\begin{array}{l}\text { Турция }(6,1), \\
\text { США }(6,1), \\
\text { Чили }(7,6)\end{array}$ \\
\hline $\begin{array}{l}\text { Коэффициент } \\
\text { дифференциации } \\
\text { P90/Р50 }\end{array}$ & 35 & 33 & 17 & 2,5 & 2,3 & 1,9 & 1,98 & $\begin{array}{c}\text { Израиль }(2,3), \\
\text { США }(2,3), \\
\text { Турция }(2,5)\end{array}$ & $\begin{array}{c}\text { Мексика }(2,8), \\
\text { Китай }(2,9), \\
\text { Чили }(3,0)\end{array}$ \\
\hline $\begin{array}{l}\text { Коэффициент } \\
\text { дифференциации } \\
\text { P50/P10 }\end{array}$ & 30 & 36 & 9 & 2,4 & 2,7 & 1,9 & 2,13 & $\begin{array}{l}\text { Латвия }(2,3), \\
\text { Греция }(2,4), \\
\text { Испания }(2,4)\end{array}$ & $\begin{array}{c}\text { Турция }(2,5), \\
\text { Чили }(2,6), \\
\text { Израиль }(2,6)\end{array}$ \\
\hline $\begin{array}{l}\text { Квинтильный } \\
\text { коэффициент } \\
\text { S80/S20 }\end{array}$ & 32 & 35 & 13 & 7,1 & 8,2 & 4,4 & 5,41 & $\begin{array}{l}\text { Греция }(6,2), \\
\text { Латвия }(6,2), \\
\text { Испания }(6,3)\end{array}$ & $\begin{array}{c}\text { Израиль }(7,3) \text {, } \\
\text { Турция }(8,0) \text {, } \\
\text { США }(8,2)\end{array}$ \\
\hline $\begin{array}{l}\text { Индекс Аткинсона } \\
(\varepsilon=0,5)\end{array}$ & 27 & 29 & 13 & 0,11 & 0,12 & 0,07 & 0,09 & $\begin{array}{c}\text { Греция }(0,09), \\
\text { Испания }(0,10), \\
\text { Эстония }(0,10)\end{array}$ & $\begin{array}{c}\text { Израиль }(0,11), \\
\text { США }(0,12), \\
\text { Китай }(0,13)\end{array}$ \\
\hline $\begin{array}{l}\text { Индекс Аткинсона } \\
(\varepsilon=1,0)\end{array}$ & 25 & 29 & 11 & $\mathbf{0 , 2 0}$ & 0,23 & 0,13 & 0,18 & $\begin{array}{c}\text { Австралия }(0,18), \\
\text { Италия }(0,18), \\
\text { Греция }(0,18)\end{array}$ & $\begin{array}{l}\text { Эстония }(0,21), \\
\text { Испания }(0,21) \text {, } \\
\text { Израиль }(0,23)\end{array}$ \\
\hline
\end{tabular}

Примечание: коэффициент Джини по рыночному доходу построен на данных дохода до выплаты налогов и социальных трансфертов.

Источник: Оценки индекса Аткинсона приведены по данным Люксембургского исследования доходов; другие показатели - по базе данных распределения доходов ОЭСР. 
По всем показателям, за исключением коэффициента дифференциации P90/P50, неравенство в России немного ниже, чем в США, хотя эти различия совсем небольшие. Из всех показателей наиболее значимые отличия между неравенством в США и России наблюдаются по коэффициенту дифференциации P50/P10 (в России - 2,4, в США - 2,7). Можно предполагать, что в России дифференциация доходов в части распределения «ниже медианы» меньше, чем в США, иначе говоря, в России существенно ниже дифференциация в нижней части распределения доходов. Это необходимо учитывать при выборе показателей неравенства и последующего их мониторинга.

Таким образом, по данным обследований населения (ОЭСР, Люксембургское исследование доходов), не включающих самых богатых россиян, неравенство по доходам в России умеренно высокое. По всем показателям неравенства, за исключением коэффициента Джини по рыночному доходу, Россия находится в верхнем квартиле стран (с самым высоким неравенством). При переоценке коэффициента Джини по рыночному доходу на аналогичный показатель по располагаемому доходу Россия перемещается в рейтинге стран с 21-го на 33-е место из 41-го, а при дооценке доходов богатых россиян с учетом налоговых данных [Guriev, Rachinsky 2009; Novokmet, Piketty, Zucman 2018] и по накопленному богатству неравенство россиян - одно из самых высоких в мире.

\section{Заключение}

В данной статье рассмотрены оценки для России основных показателей неравенства, используемые в международных исследованиях. Каждый из показателей демонстрирует картину неравенства под своим углом, имеет свои преимущества и недостатки. Наиболее предпочтительным для получения объективной картины неравенства представляется его оценивание одновременно по нескольким измерениям.

На примере коэффициента Джини показано, насколько сильно различается оценка неравенства в зависимости от используемых данных и способов расчета. Это существенно затрудняет определение допустимых границ неравенства, выше которых оно будет считаться завышенным. Проще говоря, остается вопрос, как определить, какое значение неравенства находится в пределах допустимой нормы, если по разным оценкам коэффициент Джини изменяется в диапазоне от 0,33 до 0,42 (оценки за 2013 г. Люксембургского исследования доходов и Росстата соответственно). В связи с этим межстрановые сопоставления и анализ динамики показателей с течением времени могут стать важным ориентиром при оценке приемлемости значений коэффициентов неравенства.

По большинству рассмотренных в данной статье показателей Россия относится к группе стран с умеренно высоким неравенством по доходам (выше среднего уровня ОЭСР), а с учетом дооценки доходов самого богатого верхнего дециля на основе данных по богатству и налоговой статистике она становится одним из мировых лидеров по неравенству (как по оценкам Credit Suisse, так и Т. Пикетти). В то же время важно принимать во внимание, что данные показатели не учитывают всей специфики распределения доходов россиян. 
По сравнению с другими странами, наиболее высокий уровень неравенства в России показывает показатель дифференциации P90/P50, а самый низкий - коэффициент Джини по рыночному доходу и коэффициент Аткинсона (с параметром эпсилон, равным единице и более), который более чувствителен к изменениям доходов среди бедных слоев населения. Что касается численных значений, то по всем показателям по оценкам ОЭСР, за исключением коэффициента дифференциации Р90/Р50, неравенство в России ниже, чем в США. В России разрыв между минимальными доходами десятого дециля и медианой больше, чем во всех странах ОЭСР, за исключением Чили. Из рассмотренных нами стран этот показатель выше, чем в России, также в Мексике, Китае, Бразилии и Коста-Рике. Помимо стандартных данных по дифференциации доходов (таких как коэффициент Джини и децильный коэффициент), важно учитывать и ряд других показателей, которые отражают специфику распределения доходов в России, в частности наличие тяжелых хвостов, т. е. частей распределения доходов, находящихся в левом или правом конце распределения. Так, особый интерес представляют показатели, учитывающие особенности распределения доходов россиян в концах распределений (коэффициент Пальма и др.) и чувствительные к изменению доходов среди бедных слоев населения (индекс Аткинсона, среднее логарифмическое отклонение). Для мониторинга уровня неравенства также важно проводить анализ показателей неравенства отдельно по рыночным и по располагаемым доходам, что позволит оценить вклад в перераспределение мер фискальной политики. В настоящее время эта оценка особенно полезна, поскольку увеличение трансфертов стало одним из ключевых инструментов фискальной политики в социальной сфере.

\section{Литература}

Аганбегян А.Г. (2017) Преодоление бедности и сокращение неравенства по доходам и потреблению в России // ЭКО. № 9. С. 66-86.

Аникин В.А., Тихонова Н.Е. (2016) Бедность и неравенство в странах БРИКС: российская специфика // Общество и экономика. № 1. С. 78-115.

Бурдяк А.Я. (2015) Обеспеченность жильем в постсоветской России: неравенство и проблема поколений // Журнал исследований социальной политики. Т. 13. № 2. C. $273-288$.

Бутаева К. (2017) Механизм оценки неравенства доходов в России: проблема формирования и использования. Диссертация на соискание ученой степени кандидата экономических наук. М.

Григорьев Л.М., Павлюшина В.А. (2018) Межстрановое неравенство: динамика и проблема стадий развития // Вопросы экономики. № 7. С. 5-29.

Джомо К.С., Попов В.В. (2016) Долгосрочные тенденции в распределении доходов // Журнал Новой экономической ассоциации. № 3. С. 146-160.

Зубаревич Н.В. (2013) Неравенство доходов населения: пространственная проекция // Pro et Contra. T. 17. № 6. C. 48-60.

Капелюшников Р.И. (2017) Неравенство: как не примитивизировать проблему // Вопросы экономики. № 4. С. 117-139.

Капелюшников Р.И. (2019) Экономическое неравенство - вселенское зло? // Вопросы экономики. № 4. С. 91-106.

Кислицына О.А. (2003) Неравенство доходов в России в переходный период. М.: EERC. 
Колмаков И.Б. (2015) Сопряжение логарифмически нормального распределения населения по уровню денежных доходов с распределением Парето // Аудит и финансовый анализ. № 2. С. 124-131.

Лившиц В.Н. (2017) Бедность и неравенство доходов населения в России и за рубежом. М.: Институт экономики РАН.

Любимов И.Л. (2016) Неравенство и экономический рост: теоретические аспекты зависимости. М.: РАНХиГС

Малева Т.М., Авраамова Е.М. (2014) О причинах воспроизводства социально-экономического неравенства: что показывает ресурсный подход? // Вопросы экономики. № 7. С. 144-160.

Малева Т.М., Карцева М.А., Кузнецова П.О., Салмина А.А. Меняет ли применение альтернативных методик картину неравенства в регионах России? // Регион: экономика и социология. № 2. С. 46-76 // http://recis.ru/en/region/magazine/127/2393

Методологические положения по расчету основных показателей социально-экономической дифференциации и бедности (29.10.2015 г.) (2015) // Федеральная служба государственной статистики РФ. С. 19 // http://www.gks.ru/free_doc/new_site/rosstat/NMS/prez-frol.pdf

Овчарова Л.Н., Попова Д.О., Рудберг А.М. (2016) Декомпозиция факторов неравенства доходов в современной России // Журнал Новой экономической ассоциации. № 3(31). С. $170-186$.

Шевяков А.Ю., Кирута А.Я. (2002) Измерение экономического неравенства. М.: Лето.

Шевяков А.Ю., Кирута А.Я. (2009) Неравенство, экономический рост и демография: Неисследованные взаимосвязи. М.: М-Студио.

Amiel Y., Cowell F.A. (1992) Measurement of Income Inequality. Experimental Test by Questionnaire // Journal of Public Economics, vol. 47, no 1, pp. 3-26.

Atkinson A.B., Piketty T., Saez E. (2011) Top Incomes in the Long Run of History // Journal of Economic Literature, vol. 49, no 1, pp. 3-71.

Cochrane J. (2015) How and Why We Care about Inequality // Inequality and Economic Policy: Essays in Honor of Gary Becker (eds. Church T., Miller Ch., Taylor, J.B.), Hoover Institution Press.

Commander S., Tolstopiatenko A., Yemtsov R. (1999) Channels of Redistribution: Inequality and Poverty in the Russian Transition // Economics of Transition, vol. 7, no 2, pp. 411-447.

Credit Suisse Global Wealth Report 2018 (2018), Zurich: Credit Suisse AG Research Institute.

Deaton A. (2013) The Great Escape: Health, Wealth, and the Origins of Inequality, Princeton, NJ: Princeton University Press.

Foss S., Korshunov D., Zachary S. (2013) An Introduction to Heavy-Tailed and Subexponential Distributions. Springer Series in Operations Research and Financial Engineering, New York: Springer-Verlag.

Gastwirth J. (2017) Is the Gini Index of Inequality Overly Sensitive to Changes in the Middle of the Income Distribution? // Statistics and Public Policy, vol. 4, no 1, pp. 1-11.

Guriev S., Rachinsky A. (2009) The Evolution of Personal Wealth in the Former Soviet Union and Central and Eastern Europe // Personal Wealth from a Global Perspective (ed. Davies J.B.), Oxford University Press, Oxford, pp. 134-149.

Haughton J., Khandker Sh. (2009) Handbook on Poverty and Inequality, Washington, DC: The World Bank.

Heckman J. (2011) The Economics of Inequality: The Value of Early Childhood Education // American Educator, vol. 35, no 1, pp. 31-47.

Hill B.M. (1975) A Simple General Approach to Inference about the Tail of a Distribution // The Annals of Statistics, vol. 3, no 5, pp. 1163-1174.

Ibragimov M., Ibragimov R. (2018) Heavy Tails and Upper-tail Inequality: The Case of Russia // Empirical Economics, vol. 54, no 2, pp. 823-837.

Ibragimov M., Ibragimov R., Karimov J., Yuldasheva G. (2012) Robust Analysis of Income Inequality Dynamics in Russia: t-Statistic Based Approaches // The wiiw Balkan Observatory. Working Paper. No. 105, pp. 1-37.

Lakner C., Milanovic B. (2013) Global Income Distribution: From the Fall of the Berlin Wall to the Great Recession // World Bank Policy Research Working Paper. No. 6719.

McCloskey D.N. (2014) Measured, Unmeasured, Mismeasured, and Unjustified Pessimism: A Review Essay of Thomas Piketty's "Capital in the Twenty-first Century" // Erasmus Journal for Philosophy and Economics, vol. 7, no 2, pp. 73-115. 
Maleva T.M., Kartseva M.A., Kuznetsova P.O., Salmina A.A. (2021) Does the Application of Alternative Methods Change the Pattern of Regional Inequality in Russia? // Regional Research of Russia, no 11, pp. 18-28 // https://link.springer.com/article/10.1134/S2079970521010093

Novokmet F., Piketty T., Zucman G. (2018) From Soviets to Oligarchs: Inequality and Property in Russia 1905-2016 // The Journal of Economic Inequality, vol. 16, no 2, pp. 189-223.

Piketty T. (2014) Capital in the Twenty-First Century, Cambridge Mass: Belknap Press of Harvard University Press.

Popova D., Rudberg A. (2018) Inequality in Income and Wealth in Russia // Global Encyclopedia of Public Administration, Public Policy, and Governance, Switzerland: Springer, pp. 1-12.

Stiglitz J.E. (2012) The Price of Inequality, London: Penguin Books

Stowasser T., Heiss F., McFadden D., Winter J. (2011) 'Healthy, Wealthy and Wise?' Revisited: An Analysis of the Causal Pathways from Socio-economic Status to Health // Investigations in the Economics of Aging (ed. Wise D.A.), University of Chicago Press, pp. 267-317.

Thaler R.H., Sunstein C.R. (2008) Nudge: Improving Decisions on Health, Wealth, and Happiness, New Haven, CT: Yale University Press.

Vandenbroucke F., Pissarides C. et al. (2015) Unequal Europe. Recommendations for a More Caring EU // Working Papers of Department of Economics, 487288, KU Leuven, Department of Economics, Leuven.

Yemtsov R. (2008) Through the Looking-glass: What Is behind Official Data on Inequality in Russia over 1992-2003? Paper Prepared for the 30th General Conference of the International Association for Research in Income and Wealth, Portoroz (Slovenia).

Zucman G. (2015) The Hidden Wealth of Nations: The Scourge of Tax Havens, Chicago: University of Chicago Press.

\title{
High Economic Inequality in Russia? Measurement Issues, Indicators and Evaluation 7
}

\author{
A. SALMINA*
}

\begin{abstract}
*Alla Salmina - PhD in Sociology, Senior Researcher, Institute for Social Analysis and Forecasting, Russian Presidential Academy of National Economy and Public Administration. Address: 82, bldg 1, Vernadskogo Av., Moscow, 119571, Russian Federation. E-mail: salmina-aa@ranepa.ru
\end{abstract}

Citation: Salmina A. (2021) High Economic Inequality in Russia? Measurement Issues, Indicators and Evaluation. Mir Rossii, vol. 30, no 3, pp. 78-99 (in Russian). DOI: $10.17323 / 1811-038 X-2021-30-3-78-99$

\begin{abstract}
7 The article was written on the basis of the RANEPA state assignment research programme.
\end{abstract}

The correct choice and adequate interpretation of the methodology for measuring inequality are important for understanding the specifics and depth of economic inequality 
in Russia. This article discusses the main inequality indicators used in Russia and applied in international studies. The first part of the article presents the estimates of inequality in Russia according to official statistics (Rosstat) and considers alternative estimates provided by international organizations and researchers. Special attention is paid to inequality indicators and a number of methodological aspects of measurement that need to be considered when making calculations. The author shows how selected indicators and the data used affect the assessment of inequality. She also provides inequality estimates based on accumulated wealth and discusses the specifics of income inequality in Russia, namely the presence of "heavy" distribution tails.

The second part presents a comparison of income inequality in Russia and other countries based on OECD data. According to most indicators, Russia belongs to the group of countries with moderately-high income inequality (above the average OECD level). However, considering additional income inequality estimates (e.g., the incomes of the richest decile based on wealth data and tax statistics according to the estimates of Credit Suisse and Thomas Piketty) Russia is a world leader in inequality.

In order to obtain an objective picture of inequality, it is necessary to evaluate it simultaneously in several dimensions. In addition to standard indicators of income differentiation (such as the Gini coefficient and decile coefficient), it is important to take into account a number of other indicators that reflect the specifics of income distribution in Russia, in particular, the presence of heavy tails. Of particular interest are indicators which account for such distribution specifics (e.g., the Palma coefficient) and which are sensitive to changes in income among the poor (e.g., Atkinson index, the average logarithmic deviation).

Keywords: inequality, Gini coefficient, income, wealth, taxes, Russia

\section{References}

Aganbegyan A.G. (2017) Preodolenie bednosti i sokrashchenie neravenstva po dokhodam i potrebleniyu v Rossii [Overcoming Poverty and Reducing Income and Consumption Inequality in Russia]. $E K O$, no 9, pp. 66-86.

Amiel Y., Cowell F.A. (1992) Measurement of Income Inequality. Experimental Test by Questionnaire. Journal of Public Economics, vol. 47, no 1, pp. 3-26.

Anikin V.A., Tikhonova N.E. (2016) Bednost' i neravenstvo v stranakh BRIKS: rossijskaya spetsifika [Poverty and Inequality in the BRICS Countries: Russian Specifics]. Society and Economics, no 1, pp. 78-115.

Atkinson A.B., Piketty T., Saez E. (2011) Top Incomes in the Long Run of History. Journal of Economic Literature, vol. 49, no 1, pp. 3-71.

Burdyak A.Ya. (2015) Obespechennost' zhil'em v postsovetskoj Rossii: neravenstvo i problema pokolenij [Housing Security in post-Soviet Russia: Inequality and the Problem of Generations]. The Journal of Social Policy Studies, vol. 13, no 2, pp. 273-288.

Butaeva K. (2017) Mekhanizm otsenki neravenstva dokhodov v Rossii: problema formirovaniya $i$ ispol'zovaniya [The Mechanism for Assessing Income Inequality in Russia: The Problem of Formation and Use], Moscow.

Cochrane J. (2015) How and Why We Care about Inequality. Inequality and Economic Policy: Essays in Honor of Gary Becker (eds. Church T., Miller Ch., Taylor, J.B.), Hoover Institution Press. 
Commander S., Tolstopiatenko A., Yemtsov R. (1999) Channels of Redistribution: Inequality and Poverty in the Russian Transition. Economics of Transition, vol. 7, no 2, pp. 411-447.

Credit Suisse Global Wealth Report 2018 (2018), Zurich: Credit Suisse AG Research Institute.

Deaton A. (2013) The Great Escape: Health, Wealth, and the Origins of Inequality, Princeton, NJ: Princeton University Press.

Foss S., Korshunov D., Zachary S. (2013) An Introduction to Heavy-Tailed and Subexponential Distributions. Springer Series in Operations Research and Financial Engineering, New York: Springer-Verlag.

Gastwirth J. (2017) Is the Gini Index of Inequality Overly Sensitive to Changes in the Middle of the Income Distribution? Statistics and Public Policy, vol. 4, no 1, pp. 1-11.

Grigoriev L.M., Pavlyushina V.A. (2018) Mezhstranovoe neravenstvo: dinamika i problema stadij razvitiya [Cross-country Inequality: The Dynamics and the Problem of Developmental Stages]. Voprosy Ekonomiki, no 7, pp. 5-29.

Guriev S., Rachinsky A. (2009) The Evolution of Personal Wealth in the Former Soviet Union and Central and Eastern Europe. Personal Wealth from a Global Perspective (ed. Davies J.B.), Oxford University Press, Oxford, pp. 134-149.

Haughton J., Khandker Sh. (2009) Handbook on Poverty and Inequality, Washington, DC: The World Bank.

Heckman J. (2011) The Economics of Inequality: The Value of Early Childhood Education. American Educator, vol. 35, no 1, pp. 31-47.

Hill B.M. (1975) A Simple General Approach to Inference about the Tail of a Distribution. The Annals of Statistics, vol. 3, no 5, pp. 1163-1174.

Ibragimov M., Ibragimov R. (2018) Heavy Tails and Upper-tail Inequality: The Case of Russia. Empirical Economics, vol. 54, no 2, pp. 823-837.

Ibragimov M., Ibragimov R., Karimov J., Yuldasheva G. (2012) Robust Analysis of Income Inequality Dynamics in Russia: t-Statistic Based Approaches. The wiiw Balkan Observatory. Working Paper. No. 105, pp. 1-37.

Jomo K.S., Popov V.V. (2016) Dolgosrochnye tendencii v raspredelenii dohodov [Long-term Trends in Income Distribution]. The Journal of the New Economic Association, no 3, pp. 146-160.

Kapelyushnikov R.I. (2017) Neravenstvo: kak ne primitivizirovat' problem [Inequality: How Not to Primitivize the Problem]. Voprosy Ekonomiki, no 4, pp. 117-139.

Kapelyushnikov R.I. (2019) Ekonomicheskoe neravenstvo - vselenskoe zlo? [Economic Inequality - Universal Evil?]. Voprosy Ekonomiki, no 4, pp. 91-106.

Kislitsyna O.A. (2003) Neravenstvo dokhodov v Rossii v perekhodnyj period [Income Inequality in Russia in Transition], Moscow: EERC.

Kolmakov I.B. (2015) Sopryazhenie logarifmicheski normal'nogo raspredeleniya naseleniya po urovnyu denezhnyh dohodov s raspredeleniem Pareto [Conjugation of the Logarithmically Normal Distribution of the Population in Terms of Money Income with the Pareto Distribution]. Audit i finansovyj analiz, no 2, pp. 124-131.

Lakner C., Milanovic B. (2013) Global Income Distribution: From the Fall of the Berlin Wall to the Great Recession. World Bank Policy Research Working Paper. No. 6719.

Livshits V.N. (2017) Bednost'i neravenstvo dokhodov naseleniya v Rossii i za rubezhom [Poverty and Income Inequality in Russia and Abroad], Moscow: Institute of Economics.

Lyubimov I.L. (2016) Neravenstvo i ekonomicheskij rost: teoreticheskie aspekty zavisimosti [Inequality and Economic Growth: Theoretical Aspects of Dependence], Moscow: RANEPA.

Maleva T.M., Avraamova E.M. (2014) O prichinakh vosproizvodstva social'no-ekonomicheskogo neravenstva: chto pokazyvaet resursnyj podkhod? [On the Causes of the Reproduction of Socio-economic Inequality: What Does the Resource Approach Reveal?]. Voprosy Ekonomiki, no 7, pp. 144-160.

Maleva T.M., Kartseva M.A., Kuznetsova P.O., Salmina A.A. (2020) Menyaet li primenenie al'ternativnyh metodik kartinu neravenstva v regionah Rossii? [Does the Use of Alternative Methods Change the Picture of Inequality in the Regions of Russia]. Region: ekonomika i sociologiya, no 2, pp. 46-76. Available at: http://recis.ru/en/region/magazine/127/2393, accessed 10.05.2021. 
Maleva T.M., Kartseva M.A., Kuznetsova P.O., Salmina A.A. (2021) Does the Application of Alternative Methods Change the Pattern of Regional Inequality in Russia? Regional Research of Russia, no 11, pp. 18-28. Available at: https://link.springer.com/article/10.1134/S2079970521010093, accessed 10.05.2021.

McCloskey D.N. (2014) Measured, Unmeasured, Mismeasured, and Unjustified Pessimism: A Review Essay of Thomas Piketty's "Capital in the Twenty-first Century". Erasmus Journal for Philosophy and Economics, vol. 7, no 2, pp. 73-115.

Metodologicheskie polozheniya po raschetu osnovnyh pokazatelej social'noekonomicheskoj differenciacii i bednosti (10.29.2015) [Methodological Provisions for the Calculation of the Main Indicators of Socio-Economic Differentiation and Poverty (10.29.2015)] (2015). Federal State Statistics Service, p. 19. Available at: http://www.gks.ru/free_doc/new_site/rosstat/NMS/prez-frol.pdf, accessed 10.05.2021.

Novokmet F., Piketty T., Zucman G. (2018) From Soviets to Oligarchs: Inequality and Property in Russia 1905-2016. The Journal of Economic Inequality, vol. 16, no 2, pp. 189-223.

Ovcharova L.N., Popova D.O., Rudberg A.M. (2016) Dekompoziciya faktorov neravenstva dokhodov v sovremennoj Rossii [Decomposition of Income Inequality Factors in Modern Russia]. The Journal of the New Economic Association, no 3(31), pp. 170-186.

Piketty T. (2014) Capital in the Twenty-First Century, Cambridge Mass: Belknap Press of Harvard University Press.

Popova D., Rudberg A. (2018) Inequality in Income and Wealth in Russia. Global Encyclopedia of Public Administration, Public Policy, and Governance, Switzerland: Springer, pp. 1-12.

Shevyakov A.Yu., Kiruta A.Ya. (2002) Izmerenie ekonomicheskogo neravenstva [Measuring Economic Inequality], Moscow: Summer.

Shevyakov A.Yu., Kiruta A.Ya. (2009) Neravenstvo, ekonomicheskij rost $i$ demografiya: neissledovannye vzaimosvyazi [Inequality, Economic Growth and Demography: Unexplored Relationships], Moscow: M-Studio.

Stiglitz J.E. (2012) The Price of Inequality, London: Penguin Books

Stowasser T., Heiss F., McFadden D., Winter J. (2011) 'Healthy, Wealthy and Wise?' Revisited: An Analysis of the Causal Pathways from Socio-economic Status to Health. Investigations in the Economics of Aging (ed. Wise D.A.), University of Chicago Press, pp. 267-317.

Thaler R.H., Sunstein C.R. (2008) Nudge: Improving Decisions on Health, Wealth, and Happiness, New Haven, CT: Yale University Press.

Vandenbroucke F., Pissarides C. et al. (2015) Unequal Europe. Recommendations for a More Caring EU. Working Papers of Department of Economics, 487288, KU Leuven, Department of Economics, Leuven.

Yemtsov R. (2008) Through the Looking-glass: What Is behind Official Data on Inequality in Russia over 1992-2003? Paper Prepared for the 30th General Conference of the International Association for Research in Income and Wealth, Portoroz (Slovenia).

Zubarevich N.V. (2013) Neravenstvo dokhodov naseleniya: prostranstvennaya proekciya [Income Inequality: Spatial Projection]. Pro et Contra, vol. 17, no 6, pp. 48-60.

Zucman G. (2015) The Hidden Wealth of Nations: The Scourge of Tax Havens, Chicago: University of Chicago Press. 